\title{
Efeitos na Taxa de Transporte de Elétrons de Plantas Daninhas após Aplicação de Amicarbazone ${ }^{1}$
}

\author{
Effects on the Electron Transport Rate of Weeds after Amicarbazone Application
}

\author{
ARALDI, R. ${ }^{2}$, VELINI, E.D. ${ }^{3}$, GIROTTO, M. ${ }^{2}$, CARBONARI, C.A. ${ }^{4}$, JASPER, S.P. $^{2}$ e \\ TRINDADE, M.L.B. ${ }^{4}$
}

\begin{abstract}
RESUMO - Entre os herbicidas registrados para cana-de-açúcar, o amicarbazone é um dos mais importantes para o controle das plantas daninhas, sendo preciso que o herbicida seja absorvido, translocado e que ele alcance os cloroplastos das células das folhas para atuar em seu sitio de ligação no fotossistema II. O objetivo deste trabalho foi avaliar os efeitos da aplicação do amicarbazone na taxa de transporte de elétrons (ETR) de Ipomoea grandifolia, Brachiaria decumbens e Digitaria horizontalis. Foi verificada a resposta dessas plantas daninhas, em relação à ETR, quando submetidas ao amicarbazone em solução e na sequência à solução sem herbicida, por meio de leituras da ETR, realizadas em folhas novas e adultas com o uso de um fluorômetro portátil. Verificou-se também o consumo de água das plantas daninhas pela pesagem diária dos recipientes contendo a solução e as plantas. Assim, verificou-se por meio do experimento que a redução dos valores da ETR pode ser utilizada para indicar o nivel de intoxicação nas plantas daninhas em estudo. As plantas daninhas I. grandifolia, $B$. decumbens e $D$. horizontalis apresentaram respostas diferenciadas quando submetidas a solução sem herbicida após solução com amicarbazone. I. grandifolia apresentou-se mais sensivel ao amicarbazone devido à maior dificuldade em recuperar os niveis iniciais de ETR, além de apresentar alterações nas folhas novas após o termino de fornecimento do herbicida. O consumo de água pode explicar esse comportamento em I. grandifolia, visto tratar-se da espécie que mais consumiu água e, consequentemente, mais absorveu o amicarbazone. Já para $B$. decumbens e $D$. horizontalis ocorreram menores niveis de absorção de água e, por conseguinte, as folhas velhas tiveram melhor recuperação do transporte de elétrons e não houve intoxicação em folhas novas.
\end{abstract}

Palavras-chave: ETR, fluorescência, fluorômetro, intoxicação.

\begin{abstract}
Amicarbazone is one of the most important herbicides registered for weed control in sugarcane. It must be absorbed, translocated, and reach the chloroplasts of leaf cells to act on its binding site in the photosystem II. The objective of this work was to evaluate the effects of applying amicarbazone on the electron ltransport rate (ETR) of Ipomoea grandifolia, Brachiaria decumbens and Digitaria horizontalis. The response of these weeds to ETR, was verified when submitted to amicarbazone in solution and in sequence to the solution without herbicide, by ETR readings on adult and young leaves, using a portable fluorometer. Water consumption by the weeds was also verified by daily weighing of the containers with the solution and the plants. Thus, the experiment showed that the reduction of the ETR values may be used to indicate the level of intoxication in the weeds studied. The weeds $I$. grandifolia, B. decumbens and $\boldsymbol{D}$. horizontalis showed different responses when exposed to herbicide-free solution after the solution with amicarbazone. I. grandifolia was more sensitive to amicarbazone due to the greater difficulty in recovering the initial ETR values, besides showing effects on young leaves after completion of the herbicide application. Water intake can explain this behavior of $\mathbf{I}$. grandifolia, since this species
\end{abstract}

Recebido para publicação em 1.12.2010 e aprovado em 14.2.2011.

2 Pós-Graduação em Agronomia pela Faculdade de Ciências Agronômicas, Universidade Estadual Paulista Júlio de Mesquita Filho - FCA/UNESP - Campus de Botucatu, Fazenda Experimental Lageado, Caixa Postal 237, 18603-970 Botucatu-SP, <araldi@fca.unesp.br>; ${ }^{3}$ Professor, Dr., Dep. de Agricultura, FCA/UNESP - Campus de Botucatu; ${ }^{4}$ Doutores, FCA/UNESP Campus de Botucatu, Núcleo de Pesquisa Avançada em Matologia - NUPAM. 
consumed the most water, thus absorbing amicarbazone the most. For B. decumbens and D. horizontalis, there was less water absorption, and, consequently, the old leaves had a better electron transport recovery, and the young leaves, no intoxication.

Keywords: ETR, fluorescence, fluorometer, intoxication.

\section{INTRODUÇÃO}

A infestação das plantas daninhas é um dos principais fatores bióticos presentes no agroecossistema da cana-de-açúcar; elas destacam-se pela rapidez e eficiência na utilização de água, luz e nutrientes do ambiente.

Estima-se que existam cerca de 1.000 espécies de plantas daninhas que habitam o agroecossistema de cana-de-açúcar, distribuídas nas distintas regiões produtoras do mundo (Carvalho et al., 2005). As espécies daninhas I. grandifolia e I. hederifolia e as gramineas Digitaria spp., $P$. maximum e $B$. decumbens têm sido identificadas, atualmente, como plantas daninhas de elevada ocorrência nas regiões Sudeste e Centro-Oeste, causando problemas na cultura de cana-de-açúcar (Victoria Filho \& Christoffoleti, 2004).

Para controlar essas plantas e evitar os possiveis prejuízos à cultura da cana-de-açúcar, muitos herbicidas com diferentes ingredientes ativos e formulações estão registrados para o uso no Brasil. Entre os herbicidas registrados para cana-de-açúcar, o amicarbazone é um dos mais importantes para o controle das plantas daninhas (Toledo et al., 2004). Para que ocorra o efetivo controle das plantas daninhas com a aplicação de herbicidas, é preciso que o herbicida aplicado, além de ser absorvido, translocado e redistribuido pelas plantas, chegue até o sítio de ação em quantidade suficiente para ser fitotóxico, ou seja, uma vez presente na célula, interfira nos processos vitais específicos da planta. Como o amicarbazone é um herbicida inibidor da fotossintese, tornase necessário que ele alcance os cloroplastos das células das folhas para atuar em seu sitio de ligação no fotossistema II.

O herbicida amicarbazone como inibidor da fotossíntese se liga à proteína $D_{1}$, não permitindo a transferência de elétrons entre as $Q_{A}$ e $Q_{B}$ no fotossistema II. Uma vez ligado o herbicida à proteína e estando a planta submetida a elevadas taxas de radiação fotossinteticamente ativa, ocorre a formação de radicais livres, os quais promovem a peroxidação de membranas, além do aumento da emissão de fluorescência pelo aparato fotossintético (Yamamoto, 2001).

A emissão de fluorescência fornece informações sobre os processos fotoquímicos do PSII em plantas. Sob condição de baixa luz, em torno de $95 \%$ dos fótons absorvidos são usados na fotoquímica, $4,5 \%$ são transformados em calor e $0,5 \%$ é reemitido como luz fluorescente. Se todos os centros de reação do PSII estiverem fechados por um bloqueio da fotossintese, $95-97 \%$ da energia pode ser dissipada como calor e 2,5-5,0\%, via fluorescência (Bolhàr-Nordenkampf \& Oquist, 1993).

A análise cinética da fluorescência oferece muitas vantagens como instrumento qualitativo para o estudo do transporte de elétrons durante a fotossintese, visto que o processo de obtenção de medidas da fluorescência da clorofila é rápido, específico e não destrutivo (Mohanty \& Govindjee, 1974). Com o uso de um fluorômetro, é possivel registrar o comportamento da fase inicial da fotossintese, que é o transporte de elétrons no PSII, sendo este o sítio de ação do amicarbazone.

Van Oorschot \& Van Leeuwen (1992) conduziram experimento com folhas destacadas de Alopecurus myosuroides submetidas ao chlortoluron. As folhas das plantas resistentes mostraram parcial a completa recuperação da inibição do transporte de elétrons, enquanto as plantas suscetiveis não mostraram qualquer recuperação do transporte de elétrons no PSII. Em trabalho desenvolvido por Dayan et al. (2009), foi monitorado o ETR em plantas de Digitaria sanguinalis e Abutilon theophrasti submetidas à aplicação de amicarbazone e atrazine. A taxa de transporte de elétrons para Digitaria sanguinalis e Abutilon theophrasti foi completamente inibida com oito horas de aplicação dos herbicidas. 
O objetivo deste trabalho foi avaliar os efeitos da aplicação da amicarbazone na taxa de transporte de elétrons em I. grandifolia, $B$. decumbens e $D$. horizontalis.

\section{MATERIAL E MÉTODOS}

As plantas daninhas I. grandifolia, $D$. horizontalis e $B$. decumbens foram cultivadas em tubetes preenchidos com substrato por cerca de 30 dias; após esse periodo, foram coletadas e tiveram suas raízes lavadas para remoção do substrato do sistema radicular, sendo estas colocadas em um recipiente com água por um período de 24 horas. Na sequência, as plantas foram colocadas em recipientes plásticos, de forma que suas raízes tivessem contato com uma solução de amicarbazone na concentração de $0,250 \mathrm{mg} \mathrm{L}^{-1}$. Essa concentração foi selecionada a partir dos resultados observados na solução do solo em condições de campo, conforme Carbonari (2009). Os recipientes contendo as plantas e a solução com o herbicida foram cobertos com papel-aluminio, de forma a evitar a evaporação da solução do herbicida, permitindo verificar o consumo de água das plantas daninhas em estudo durante todo o período, monitorado através da pesagem diária.

Após intervalo de tempo suficiente para que o fluxo de elétrons fosse inibido (48 horas), as plantas daninhas em contato com a solução de amicarbazone tiveram o sistema radicular lavado e foram colocadas novamente para absorver solução nutritiva sem herbicida. Foi utilizada solução nutritiva para que as plantas emitissem folhas novas, o que permitiu verificar a mobilidade do amicarbazone nas plantas após a interrupção do fornecimento do herbicida. Assim, as folhas foram classificadas como folha adulta e folha nova. A folha nova surgiu apenas nas últimas avaliações monitoradas.

$\mathrm{O}$ experimento foi instalado e mantido em casa de vegetação, sendo utilizado um delineamento inteiramente casualizado, com seis repetições. Aos 0, 4, 24, 48, 96, 144, 192, 240, 288 e 336 horas após o primeiro contato do sistema radicular com a solução de amicarbazone, foram registradas as leituras de ETR, na porção mediana das folhas, com o uso de um fluorômetro, modelo Multi-Mode Chlorophyll Fluorometer OS5p (Opti-Sciences).
Com o fluorômetro, é possível registrar o comportamento da fase inicial da fotossintese, que é o transporte de elétrons no PSII, sendo este o sítio de ação do amicarbazone. A fonte de luz utilizada para medir a fluorescência no aparelho foi a diodo com pico de luz vermelha no comprimento de onda de $660 \mathrm{~nm}$, sendo bloqueadas radiações maiores que $690 \mathrm{~nm}$. A intensidade média da luz foi ajustada para o intervalo de 0 a $1 \mu \mathrm{Mol} \mathrm{m} \mathrm{m}^{-2} \mathrm{~s}^{-1}$, com o uso da lâmpada halogênica $35 \mathrm{~W}$. O feixe de luz é opticamente monitorado no interior da câmara para corrigir as variações devido a mudanças na temperatura do ambiente. Os sinais ópticos são transferidos para a superfície da folha por uma trifurcação personalizada de fibra óptica, sendo de $2 \mathrm{~cm}^{2}$ a área iluminada. A luz reemitida é conduzida via fibra óptica para o aparelho por meio de três conectores ligados à lateral do OS5p. As análises foram feitas seguindo a metodologia de Genty et al. (1989), avaliando a emissão da fluorescência da clorofila na superficie superior das folhas.

Para iluminação e detecção da fluorescência da clorofila das amostras de plantas daninhas estudadas no trabalho, foi utilizado o protocolo Yield para a mensuração da taxa de transporte de elétrons. Esse protocolo é otimizado para um estado da fotossintese adaptado à luz porque registra as medidas de quantum efetivo produzido no PSII. Tanto a fonte de luz do sol quanto a luz artificial podem ser usadas para dirigir a fotossintese.

Taxa de transporte de elétrons (ETR) $\mu$ mols elétrons $\mathrm{m}^{-2} \mathbf{s}^{-1}=(\mathrm{Y})$. $(\mathrm{PAR}) \cdot(0,84) \cdot(0,5)$ é equivalente a: (produção de quantum do PSII) $\mathrm{x}$ (medidas da radiação fotossinteticamente ativa medida em $\mu$ mols elétrons $\mathrm{m}^{-2} \mathrm{~s}^{-1}$ ) $\mathrm{x}$ (coeficiente de absorção da folha) x (fração de luz absorvida pelo complexo antena do PSII). O ETR é uma medida da separação de cargas do centro de reação do PSII. Na equação são usados valores-padrão, porém ambos os coeficientes de absorção e fração da luz absorvida pelo PSII podem ser trocados. Embora 0,84 seja um valor médio para muitas espécies de plantas, trabalhos têm mostrado que o coeficiente de absorção da folha pode variar com a qualidade da luz, espécie, conteúdo de clorofila e refletância da folha. Para a fração de luz que é absorvida pelo complexo antena do PSII, os trabalhos mostram que ocorre variação de acordo com a 
espécie, que se estende de 0,42 a 0,60 (Laisk \& Loreto, 1996).

Assim, o parâmetro ETR determina a taxa de transporte de elétrons fotossintéticos no PSII, e o uso do valor do ETR permite detectar o efeito da atuação do herbicida em nivel de concentração de 0,5 micromoles $\mathrm{dm}^{-3}$; já o método tradicional, que inclui a medição do parâmetro Fv/Fm, permite detectar apenas em um nivel de concentração, que é 100 vezes maior (Korres et al., 2003; Abbaspor et al., 2006).

Os dados foram submetidos à análise de variância pelo teste $\mathrm{F}$ a $5 \%$ de probabilidade, e a comparação das médias foi feita pelo teste $\mathrm{t}$ a $10 \%$ de probabilidade.

\section{RESULTADOS E DISCUSSÃO}

Nas Figuras 1, 2 e 3 encontram-se os dados que descrevem o comportamento do ETR para I. grandifolia, $B$. decumbens e $D$. horizontalis, respectivamente, quando mantidas com o sistema radicular imerso em solução com amicarbazone e, após 48 horas, em solução sem herbicida (solução nutritiva).

Para I. grandifolia, quatro horas após a disponibilidade do herbicida em solução houve redução de $34 \%$ do ETR para a folha adulta, em relação ao valor de ETR inicial da planta sem herbicida. Com 24 horas após a aplicação, a folha atingiu os $55 \%$ de redução do ETR; 48 horas após a aplicação, a inibição foi de $87 \%$ para a folha adulta de I. grandifolia. Nos intervalos de monitoramento seguintes ocorreu leve recuperação do transporte de elétrons devido à substituição da solução de herbicida pela solução nutritiva, mantendo os valores de ETR próximos a $50 \mu$ mols elétrons $\mathrm{m}^{-2} \mathbf{s}^{-1}$. Assim, com 96 horas após a aplicação a folha adulta recuperou $15 \%$ do ETR em relação à última avaliação, de 48 horas (Figura 1).

Às 192 horas após o início do experimento surgiu uma folha nova de I. grandifolia, com valor de ETR muito próximo ao das folhas no momento inicial do experimento. No último período monitorado, 336 horas após o início do ensaio, essa folha nova apresentou redução do ETR de $26 \%$ em relação ao momento zero.

Esse comportamento de mínima recuperação do ETR para a folha adulta após a inibição do transporte de elétrons e leve redução do ETR para a folha nova possivelmente esteja relacionado à presença de resíduos do amicarbazone no sistema vascular das plantas de I. grandifolia mesmo depois de 288 horas após a substituição da solução herbicida pela solução nutritiva.

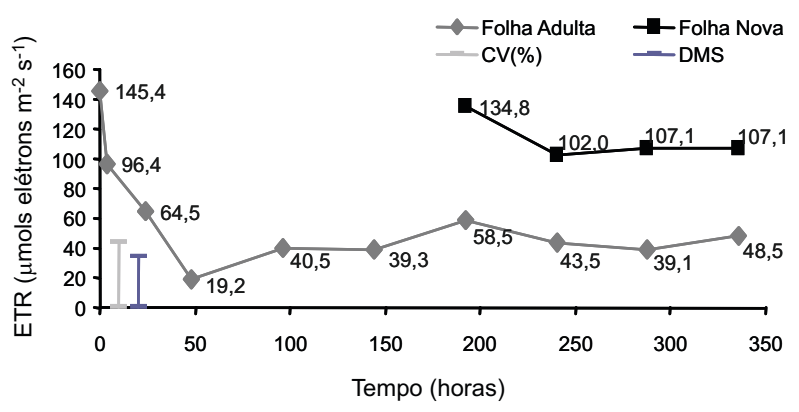

Figura 1 - Comportamento da taxa de transporte de elétrons (ETR) em relação ao tempo, em horas, para folha nova e adulta da espécie daninha I. grandifolia. Botucatu-SP, 2010. CV (\%) é o coeficiente de variação, e DMS, a diferença mínima significativa pelo teste t a $10 \%$ de probabilidade.

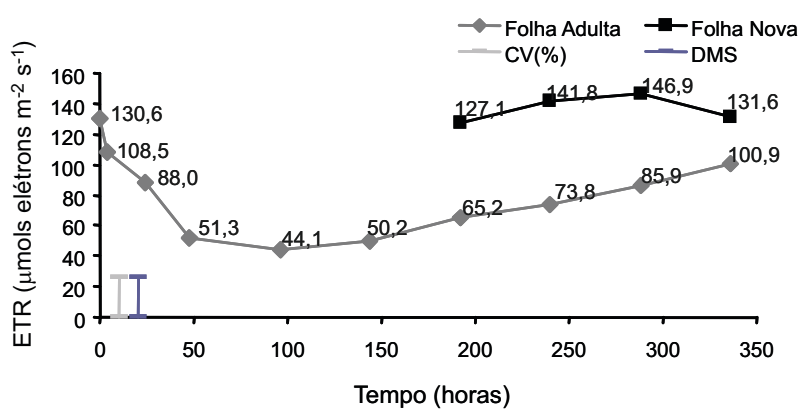

Figura 2 - Comportamento da taxa de transporte de elétrons (ETR) em relação ao tempo, em horas, para folha nova e adulta da espécie daninha B. decumbens. Botucatu-SP, 2010. CV (\%) é o coeficiente de variação, e DMS, a diferença mínima significativa pelo teste $\mathrm{t}$ a $10 \%$ de probabilidade.

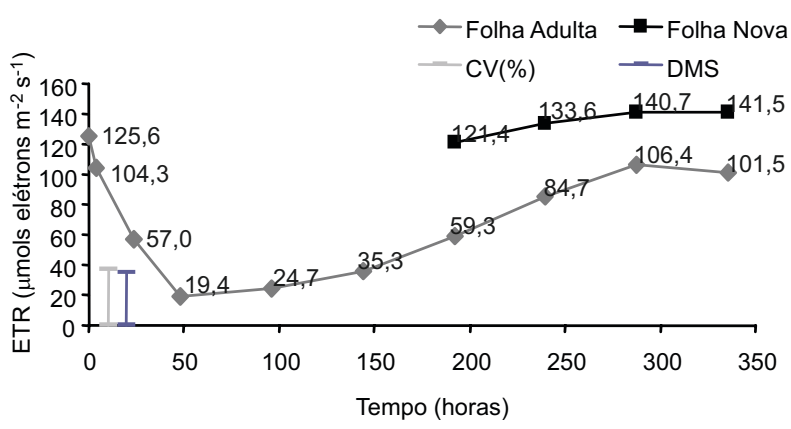

Figura 3 - Comportamento da taxa de transporte de elétrons (ETR) em relação ao tempo, em horas, para folha nova e adulta da espécie daninha D. horizontalis. Botucatu-SP, 2010. CV (\%) é o coeficiente de variação, e DMS, a diferença mínima significativa pelo teste t a $10 \%$ de probabilidade. 
As pequenas oscilações do ETR ocorridas ao longo do período avaliado devem-se às condições do ambiente, visto que a capacidade fotossintética das plantas pode ser alterada por estresses bióticos ou abióticos pelos quais as plantas podem passar, como temperatura, radiação, deficiência hídrica, salinidade, presença de insetos ou fungos, entre outros (Bown et al., 2002; Oliveira et al., 2002).

Para B. decumbens (Figura 2), com quatro horas após a disponibilidade do herbicida em solução ocorreu redução de $17 \%$ do ETR para a folha adulta, em relação ao valor de ETR inicial das folhas sem herbicida. Com 48 horas após a aplicação, essa folha atingiu $60 \%$ de redução da taxa de transporte de elétrons.

Nos intervalos seguintes, após a substituição da solução herbicida pela solução nutritiva, houve tendência de recuperação dos valores de ETR para a folha adulta monitorada de $B$. decumbens, com destaque para a rapidez na recuperação da fotossintese, quando comparada a I. grandifolia.

No intervalo de 96 horas após a aplicação, a folha adulta manteve comportamento parecido com o da avaliação anterior, com redução de $66 \%$ do ETR. No intervalo de 192 horas após a aplicação houve recuperação do ETR de $16 \%$ em relação ao intervalo avaliado de 96 horas. Ainda, para a avaliação de 192 horas após o início do ensaio, observou-se o surgimento da folha nova de $B$. decumbens, com valor de ETR muito próximo do das demais folhas no momento inicial do ensaio. No último período monitorado (336 horas) essa folha nova superou o valor de ETR da folha adulta encontrada no momento inicial do experimento. A folha adulta manteve ainda redução de $23 \%$ do ETR em relação ao momento inicial, em que as plantas estavam ainda sem herbicida em solução. Destaca-se também que algumas pequenas oscilações do ETR no período avaliado devem-se às condições do ambiente (Mazza et al., 2000).

Para $D$. horizontalis, com quatro horas após a disponibilidade do herbicida em solução, ocorreu redução de $17 \%$ do ETR para a folha adulta, em relação ao valor de ETR inicial da folha sem herbicida. Com 24 horas após a aplicação essa folha atingiu os 55\% de redução do ETR. Com 48 horas após a aplicação do amicarbazone, os valores foram próximos da inibição do transporte de elétrons nas folhas, com redução de $85 \%$ do ETR (Figura 3 ).

Nos intervalos seguintes, após a substituição da solução herbicida pela solução nutritiva, houve tendência de recuperação dos valores de ETR para a folha monitorada de $D$. horizontalis, com destaque para a rapidez na recuperação da fotossintese. Para $B$. decumbens ocorreu comportamento similar, em que a folha adulta também recuperou o ETR rapidamente, mas para I. grandifolia a recuperação do ETR praticamente não ocorreu (Figuras 1 e 2).

No intervalo de 96 horas após a aplicação, a folha adulta de $D$. horizontalis manteve comportamento parecido com o da última avaliação, com redução de $80 \%$ do ETR. Contudo, no intervalo monitorado de 192 horas após a aplicação houve recuperação mais significativa do ETR, sendo de $27 \%$ em relação ao intervalo avaliado de 96 horas.

Após 192 horas do início do experimento surgiu a terceira folha de $D$. horizontalis, com valor de ETR muito próximo do das demais folhas no momento inicial do experimento. No último período monitorado, de 336 horas após a aplicação do herbicida, essa folha nova superou o valor de ETR inicial da folha adulta. Ressalta-se, assim, a ausência do amicarbazone nas folhas novas de D. horizontalis, assim como ocorreu com B. decumbens. Apenas I. grandifolia apresentou indícios do amicarbazone na folha nova das plantas, o que é justificado possivelmente pelo maior comprimento do caule da espécie, quando comparado ao das gramíneas $B$. decumbens e $D$. horizontalis.

Ainda para o periodo de 336 horas, a folha adulta também se destacou pela recuperação do transporte de elétrons, mantendo o ETR 20\% menor em relação ao momento inicial, em que as plantas estavam ainda sem herbicida em solução.

Entre as espécies daninhas estudadas houve diferenças de sensibilidade em relação ao amicarbazone. I. grandifolia demonstrou ser mais sensivel quando comparada a $B$. decumbens e $D$. horizontalis, visto a baixa recuperação do ETR para as folhas após a 
substituição da solução herbicida. Negrisoli et al. (2007) constataram elevada eficácia do amicarbazone no controle de I. grandifolia, com alta sensibilidade aos tratamentos com o herbicida.

Diferença na sensibilidade a herbicidas foi observada também em plantas daninhas anuais com o uso do glufosinato. Ridley \& Mc Nalley (1985) mensuraram uma diferença de $70 \%$ na tolerância entre sete espécies de plantas daninhas anuais. Steckel et al. (1997) encontraram diferença maior que três vezes em relação à tolerância para o glufosinato entre Chenopodium album e Setaria faberi.

Em trabalho desenvolvido por Dayan et al. (2009), foi monitorado o ETR em plantas de milho, Digitaria sanguinalis e Abutilon theophrasti, quando submetidas à aplicação de amicarbazone. A taxa de transporte de elétrons para Digitaria sanguinalis e Abutilon theophrasti foi completamente inibida com oito horas após a aplicação do herbicida, enquanto o milho manteve redução de aproximadamente $70 \%$ do ETR fotossintético 24 horas após a aplicação do amicarbazone, sendo o milho mais tolerante ao herbicida testado, quando comparado às plantas daninhas.

Na Figura 4 estão apresentados os resultados de consumo de água acumulado para I. grandifolia, B. decumbens e D. horizontalis, mantidas em solução com amicarbazone até o intervalo de 48 horas após início do ensaio. I. grandifolia destacou-se pelo maior consumo de água, seguida de $D$. horizontalis e de $B$. decumbens (Figuras 4 e 5). Possivelmente esse maior consumo de água de I. grandifolia justifique a maior sensibilidade desta ao amicarbazone, pela maior absorção do herbicida.

Na Figura 5 encontraram-se os resultados de consumo de água acumulado para I. grandifolia, B. decumbens e D. horizontalis submetidas à solução com amicarbazone e, na sequência, em solução nutritiva. $O$ consumo de água para essas três espécies foi reduzido até o período de 48 horas após a aplicação do amicarbazone; posteriormente, com a substituição da solução, ocorreu a recuperação do consumo de água pelas plantas, aumentando com o passar do tempo, possivelmente em função da recuperação lenta da fotossintese

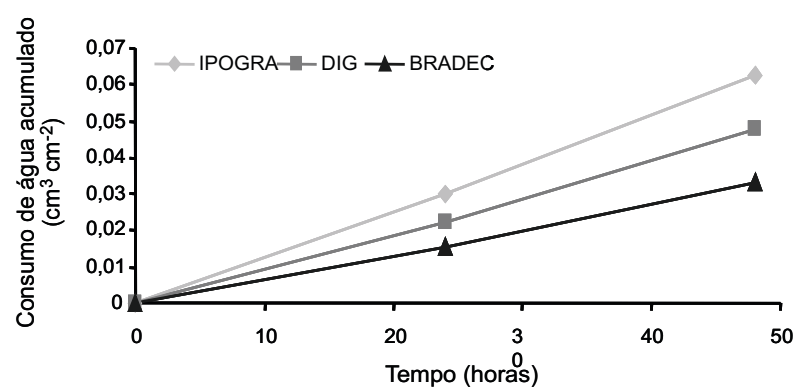

Figura 4 - Consumo de água acumulado em relação ao tempo para I. grandifolia, B. decumbens e D. horizontalis submetidas a solução com amicarbazone. Botucatu-SP, 2010. IPOGRA-Ipomoea grandifolia; DIG-Digitaria horizontalis; BRADEC-Brachiaria decumbens.

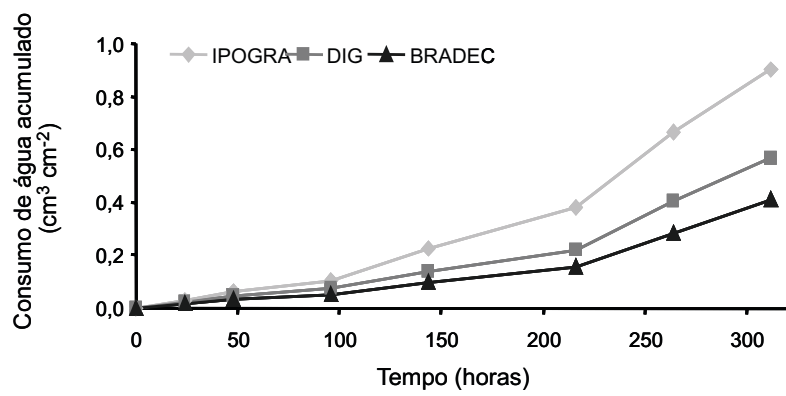

Figura 5 - Consumo de água acumulado em relação ao tempo para I. grandifolia, B. decumbens e D. horizontalis. BotucatuSP, 2010. IPOGRA - Ipomoea grandifolia; DIG - Digitaria horizontalis; BRADEC - Brachiaria decumbens.

e da transpiração das plantas daninhas (Figura 5).

Pôde-se verificar que as plantas daninhas I. grandifolia, B. decumbens e $D$. horizontalis mostraram respostas diferenciadas quando submetidas a uma solução nutritiva após solução com amicarbazone. I. grandifolia apresentou-se mais sensivel ao amicarbazone em razão da maior dificuldade em recuperar os niveis iniciais de transporte de elétrons, além de apresentar alterações nas folhas novas após o término de fornecimento do herbicida. O consumo de água pode explicar esse comportamento em I. grandifolia, visto tratar-se da espécie que mais consumiu água e, consequentemente, mais absorveu o amicarbazone.

Assim, verificou-se que a redução dos valores do ETR pode ser utilizada para indicar o nivel de intoxicação nas plantas daninhas em estudo. As plantas daninhas I. grandifolia, 
B. decumbens e $D$. horizontalis apresentaram respostas diferenciadas quando submetidas a solução sem herbicida após solução com amicarbazone. A maior absorção de água das plantas possivelmente esteja correlacionada com a maior absorção do amicarbazone e maior intoxicação das plantas em estudo.

\section{LITERATURA CITADA}

ABBASPOOR, M.; TEICHER H. B.; STREIBIG, J. C. The effect of root-absorbed PSII inhibitors on Kautsky curve parameters in sugar beet. Weed Res., v. 46, n. 3, p. 226-235, 2006.

BÒLHAR-NODENKAMPF, H. R.; OQUIST, G. O Chlorophyll fluorescence as a tool in photosynthesis research. In: HALL, D. O. et al. (Eds.). Photosynthesis and production in a changing environment. London: Chapman \& Hall, 1993. p. 193-206.

BOWN, A. W.; HALL, D. E.; MACGREGOR, K. B. Insect footsteps on leaves stimulate the accumulation of 4aminobutyrate and can be visualized through increased chlorophyll fluorescence and superoxide production. Plant Physiol., v. 129, n. 4, p. 1430-1434, 2002.

CARBONARI, C. A. Efeito da palha na disponibilidade do herbicida amicarbazone na solução do solo em áreas cultivadas com cana-de-açúcar. 2009. 101 f. Tese (Doutorado em Agronomia/Proteção de Plantas) Universidade Estadual Paulista, Botucatu, 2009.

CARVALHO, S. J. P.et al. Curvas de dose-resposta para avaliação do controle de fluxos de emergência de plantas daninhas pelo herbicida imazapic. Planta Daninha, v. 23, n. 3, p. 535-542, 2005.

DAYAN, F. E.; TRINDADE, M. L. B.; VELINI, E. D. Amicarbazone, a new photosystem II inhibitor. Weed Sci., v. 57, n. 6 , p. $579-583,2009$.

GENTY, B.; BRIANTAIS, J. M.; BAKER, N. R. The relationship between the quantum yield of photosynthetic electron-transport and quenching of chlorophyll fluorescence. Biochim. Biophys. Acta, v. 990, n. 1, p. $87-92,1989$

KORRES, N. E.; FROUD-WILLIAMS, R. J.; MOSS, S. R. Chlorophyll fluorescence technique as a rapid diagnostic test of the effects of the photosynthetic inhibitor chlortoluron on two winter wheat cultivars. Ann. Applied Biol., v. 143, n. 7, p. 53-56, 2003.
LAISK, A.; LORETO, F. Determining photosynthetic parameters from leaf $\mathrm{CO}_{2}$ exchange and chlorophyll fluorescence. Ribulose-1,5-bisphosphate carboxylase/ oxygenase specificity factor, dark respiration in the light, excitation distribution between photosystems, alternative electron transport rate, and mesophyll diffusion resistance. Plant Physiol., v. 110, n. 3, p. 903-912, 1996.

MAZZA, C. A. et al. Functional significance and induction by solar radiation of ultraviolet-absorbing sunscreens in fieldgrown soybean crops. Plant Physiol., v. 122, n. 1, p. $117-126,2000$.

MOHANTY, P.; GOVINDJEE, S. The slow decline and the subsequent rise of chlorophyll fluorescence transients in intact algal cells. Plant Biochem. J., v. 1, n. 2, p. 78-106, 1974.

NEGRISOLI, E. et al. Controle de plantas daninhas pelo amicarbazone aplicado na presença de palha de cana-deaçúcar. Planta Daninha, v. 25, n. 3, p. 603-611, 2007.

OLIVEIRA, J. G.; ALVES, P. L. C. A.; MAGALHÃES, A. C. The effect of chilling on the photosynthethic activith in coffe (Coffea arabica L.) seedlings. The protective action of chloroplastid pigments. Braz. J. Plant Physiol., v. 14, n. 2, p. $95-104,2002$

van OORSCHOT, J.L.P.; van LEEUWEN, P.H. Use of fluorescence induction to diagnose resistance of Alopecurus myosuroides Huds. (black-grass) to chlorotoluron.

Weed Res., v. 32, n. 5, p. 473-482, 1992

RIDLEY, S. M.; MCNALLY, S. F. Effects of phosphinothricin on the isoenzymes of glutamine synthetase isolated from plant species which exhibit varying degrees of susceptibility to the herbicide. Plant Sci., v. 39, n. 1, p. 31-36, 1985.

STECKEL, G. J.; HART, S. E.; WAX, L. M. Absorption and translocation of glufosinate on four weed species. Weed Sci., v. 45, p. $378-381,1997$.

TOLEDO, R. E. B. et al. Dinamic (amicarbazone) - novo herbicida seletivo para o controle de plantas daninhas em pré e pós-emergência na cultura da cana-de-açúcar. In: CONGRESSO BRASILEIRO DA CIÊNCIA DAS PLANTAS DANINHAS, 24., 2004, São Pedro. Anais... São Pedro: Sociedade Brasileira da Ciência das Plantas Daninhas, 2004. p. 451.

VICTORIA FILHO, R.; CHRISTOFFOLETI, P. J. Manejo de plantas daninhas e produtividade da cana. Visão Agric., v. 1, n. 1, p. 32-37, 2004

YAMAMOTO, Y. Quality control of photosystem II. Plant Cell Physiol., v. 42, n. 2, p. 121-128, 2001. 